\title{
Knowledge Map: Suggestions for Primary and Secondary School Teachers Training from the Perspective of Supply-side*
}

\author{
Ning Wang \\ Nanjing Xiaozhuang University \\ Nanjing, China 211171
}

\begin{abstract}
Professional training is an important way for primary and secondary school teachers' professional growth and development. From the perspective of supply-side, the current primary and secondary school teachers training focuses on the tools function of external supply. Primary and secondary school teachers training do not attach the importance to the subjectivity, does not meet the need of personalized learning supply from the demand side, and does not embody the democratization of effective training activities. Primary and secondary school teachers' enthusiasm of study, experience and ability has not been released. It is a beneficial exploration to construct the primary and secondary school teachers-centered, personalized and democratic knowledge map.
\end{abstract}

Keywords-primary and secondary school teachers training; supply-side optimization; knowledge map

\section{INTRODUCTION}

The primary and secondary school teachers training is an important link that supports the development of basic education and promote the professional growth and development of primary and secondary school teachers. It is the main way for professional development in career of primary and secondary school teachers to receive various forms of training. The supply system of primary and secondary school teacher training activities in China is mainly based on the supply of training services from external institutions such as school-based training - district (county) teachers training center (continuation school, Learning Resources Center) --- training centers held by colleges and universities (teachers educational institutions) and so on. Since China promulgated the Action Plan for Education and Rejuvenation in the 21 st Century in 2000, training activities grow vigorously every year and there are many projects. However, the abundant external supply cannot hide the lack of internal motivation and initiative of teachers, so how to master, absorb, and internalize the training content of primary and secondary schools teachers, and transform it

*[Project of the Fund] Key Project of Philosophy and Social Sciences of Universities in Jiangsu Province, "Study on Management Change in the Transformation and Development of Local Undergraduate Colleges in Jiangsu Province: An Analysis from the Perspective of Supply-side", project number 2016ZDIXM031 into educational and teaching practice is a real problem. This kind of supply method shows the phenomena of "over training and gilded training"[1] and the "soft resistance" of primary and secondary school teachers, which are worth pondering and improving [2]. Even the fashionable "Internet + " teacher training has been criticized for "intensifying formalization and losing a sense of ritual in classroom teaching." The problems that primary and secondary schools teachers' subjectivity is not paid attention to, supply of personalized learning demand is not satisfied, the teaching democratization in training activities is not carried out, the enthusiasm, experience and ability of primary and secondary school teachers for learning cannot be released and so on still exist.

\section{REALISTIC CHALlENGES FACED BY PRIMARY AND SECONDARY SCHOOLS TEACHER TRAINING}

Teachers' work of primary and secondary schools teachers is not only a profession, but also a study profession, and the study profession requiring professional study. The study profession requires professional study, so only learners can become educators, and on-the-job training should become the rights and obligations of all teachers, as well as a continuous process of educational innovation. [3] This has brought about the long-term and complex professional growth and development of primary and secondary school teachers. Training is the most common way for professional growth and development of primary and secondary school teachers. In order to enhance the effectiveness and pertinence of training, educational administrative departments and training providers (schools) have carried out a large number of fruitful works, and both the quantity and quality of external training services have been greatly improved. "The current mainstream model of teacher's professional development in China is initiated by local governments (in fact, including the national central institutions such as the Ministry of Education), which is the mandatory teacher development model and the development model of providing courses, workshops, seminars and lectures by universities, mainly relying on the rigid promotion of policy system and external shaping of the training system." [4] Due to the individual differences of the participants and the diversity of the teaching environment, it is obviously not enough to 
provide training services only through a single channel from external supply. In the face of different groups of primary and middle school students and different school conditions, it is obviously impossible to meet the needs of primary and middle school teachers' professional growth and development by forming a patchwork training project and training content according to subjective experience and teachers who can be invited without considering the requirement of differentiation and diversification. Some studies have found that "the phenomena of the conjecture of the design of teacher training in primary and secondary schools, formalization of the training process, the falsification of training effects, and the virtualization of training evaluation are severe, [5]which not only make the majority of primary and secondary school teachers have the feeling that they could not get down to earth in participating in the training activities, but the constant suppression and weakening of teachers' intrinsic motivation of selfdevelopment is also very detrimental to the professional development of teachers since in the implementation process of many training activities, primary and secondary school teachers are always in the passive role of the trainees in a variety classes of experts, famous teachers, and professors.

How to activate the self-motivation and intrinsic initiative of the professional development of primary and secondary school teachers to become the main body of training activities is always a realistic problem and challenge in the training activities of primary and secondary school teachers. For a long time, training organizers and managers of primary and secondary school teachers, as well as primary and secondary school teachers groups have been thinking about how to improve training activities, including training primary and secondary school teachers in different classification, and increasing the proportion of school-based training (SBT) in the training organization system, but they has not obtain obvious effect. In fact, in the face of this problem, it is necessary to reflect on the mismatch between the way of training supply and the demand of the development of primary and secondary school teachers. This mismatch can be tackled with the help of supply-side reform thinking, but the author suggests that knowledge map of primary and secondary school teacher training should be developed and built from the angle of optimizing the supplyside service of primary and secondary school teacher training - a knowledge map of professional growth and development for university students who have never done the job but is willing to move towards the post of primary and secondary school teacher, new teachers, skilled teachers, backbone teacher, expert teachers and educators, so that teachers have the autonomy to choose the future professional development according to the content of knowledge and development direction required by the future professional development, construct the learning process scheme that meets their own needs, improve the achievement of professional development and learning interest, and form a personalized professional development planning and implementation path. Thus, the primary and secondary school teachers can actively seek a matching road map of knowledge growth in accordance with their own needs.

\section{ANALYSIS ON THE NECESSITY OF ESTABLISHING KNOWLEDGE MAP FOR PRIMARY AND MIDDLE SCHOOL TEACHERS' TRAINING}

Proceeding from the practical problem that the professional growth and development of primary and secondary school teachers mainly rely on external dynamics currently, it is a positive and beneficial exploration to think about how to mobilize the intrinsic learning initiative and motility of primary and secondary school teachers. The establishment of the knowledge map of primary and secondary schools teacher training is an attempt to make the primary and secondary school teacher training activities form a visual navigation system of knowledge and ability. The system provides a variety of integration and management tools for training and learning resources, and communicate the external training supply and the internal active supply of training of primary and secondary school teachers through the distinction between training services, so as to promote the active professional development of primary and secondary school teachers and make them transform to personalized active learners.

The function of the traditional map is to help people find the destination they want to reach. The professional growth and development of primary and secondary school teachers has a clear goal, but it is obviously not enough to only rely on external training to reach the destination of professional development, and it also wastes the great potential and rich experience of teachers as knowledge-based adult learners to a large extent. With the help of the knowledge map of primary and secondary school teacher training, every primary and secondary school teacher can turn on an automated navigation system, to find their own "gas station" and "service area" in the vast knowledge ocean and ability training system, and find the learning opportunities they can get, the learning resources they need and the self-evaluation methods on knowledge map. This kind of visualization tool is similar to road sign with clear guiding function, and can play a leading role.

The particularity and individual difference of professional growth and development of primary and secondary school teachers indicate that teachers need the support of multiple knowledge, ability and resources in this process. It is gradually becoming the consensus of the majority of primary and secondary school teachers, administrators of education departments, teachers' education research and practice experts that the professional growth and development of primary and secondary school teachers needs a combination of knowledge and ability. The supply through offering courses (lectures) only aiming for ideology and morality, professional knowledge, professional skills, teaching and research, and management skills in primary and secondary schools teacher training activities is obviously not enough. Knowledge map is a kind of knowledge management tool that can converge the explicit and tacit knowledge involved in teacher's professional development through various forms such as systematic knowledge output and induction, design and management, and reconstruction and extension, and then play the role of knowledge lever after the integration of learning resources and management, 
successful promoting professional growth and development of primary and secondary school teachers.

Multi-level external training supply is not useless, but it is also improving towards the benign status of partnerships. [6] However, such training resources supply is also characterized by significant simplification and enhancement. The training supply in the perspective of knowledge map doesn't mean to abandon the external training, but it integrates it in the whole process of the professional growth and development of primary and secondary school teachers. At the same time, individual differences of the professional growth and development of primary and secondary school teachers show that only the supply mode of training with multi-resource and multiple sources is more in line with the needs of reality. The knowledge map is a democratic guideline for supply. It not only is the tool that primary and secondary school teachers can make self-awareness, selfreflection, self-selection and self-learning, but also flexibly combines the external training and teacher' self-initiative development, playing the role of bridge; teachers can also acquire the professional development consulting and guidance with the help of colleagues, experts and scholars of external supply and gain more professional guidance and assistance in personal professional development.

Primary and secondary school teachers are mature lifelong learners, as well as learners with complex and diverse requirements for learning activities. With the multiplicity of professional role, family role and social role of primary and secondary school teachers, their learning initiative is directly related to their own knowledge structure, learning basis, team (school) environment, personal experience, time arrangement, and interest preference, and so on. Knowledge maps provide a guiding path for the knowledge and capacity spectrum. Teachers can select random selection and combination conforming to their own personalized needs according to their own interests, ability, time, intention and the clear pursuit of career development. They are not only the learners of knowledge, but also the constructors of their own knowledge, ability and resource system. It plays the role of private customized service.

If we regard the professional growth and development of primary and secondary school teachers as a professional journey, teachers as travelers need a training ship to see the grand occasion in other side of professional development. Such a professionally developed ship is inseparable from an effective professional development map as a guide and compass. With the knowledge and accumulated experience of the existing primary and secondary school teacher training programs, it is time to develop a knowledge map for the professional growth and development of teachers.

\section{THE FunCTION OF KNOWLEDGE MAP OF PRIMARY AND SECONDARY TEACHER}

Some scholars believe that "a knowledge map is a combination of information and knowledge. The former includes documents, Web pages on the Internet and extranet, document management systems, best practice records, databases, data warehouses, and data markets, while the latter is expert knowledge, rules, workflow, craft manuals, recipes and charts, etc." [7]In fact, this is not yet complete, because the knowledge map in this definition angle only focuses on the explicit knowledge of the knowledge system. In addition to the explicit knowledge mentioned above, knowledge maps of training and professional development of primary and secondary schools teacher should also include the tacit knowledge of primary and secondary school organizations, teacher groups and individuals. It should not only provide the stock, structure, function, address and query path of knowledge resources, but also point out the types and characteristics of the relevant knowledge resources both inside and outside the organization as well as the interrelationship between different types of knowledge. As a guide for primary and secondary school teachers training and professional growth and development, knowledge map need not only to have rich content and sound system, but also play a unique and important role in primary and secondary teacher training activities; therefore, the main function of knowledge map for primary and secondary teacher training is not only enumerating the content of knowledge, but also about pointing out the location or source of knowledge needed by professional growth and development of primary and secondary school teachers, and showing personnel, processes, content, and relationships with each other. Specifically, the knowledge map of primary and secondary school teachers training should play a role in the following aspects:

First of all, the knowledge map of primary and secondary school teacher training should be a collection of subjective and objective knowledge resources. That is to say, it should be able to tell the teachers in need the most basic functions and methods to find of knowledge (nodes) autonomously and have the same function as the navigation instrument.

Second, it should be able to clearly and orderly prompt the logical connection between different knowledge nodes, exchange (learning resources) relation, extraction (learning and research) means, evaluation methods and path of extensible development.

The third is to increase the value-added role of knowledge wealth. The role of fragmented knowledge resources cannot be ignored, so the advantage of knowledge maps lies in the rational integration of fragmented knowledge to form a modular knowledge unit and knowledge chain and make the resources have added value.

The fourth is the value of tacit knowledge. The knowledge map for primary and secondary school teacher training not only presents education and teaching knowledge of intuitive professional growth and development, but also includes resources for individual professional growth and development of primary and secondary school teachers, especially the growth experience of outstanding teachers among primary and secondary school teachers, accumulation of teaching fragments, course video of lecturers providing help for primary and secondary schools teacher training, of course, and the hidden and flexible knowledge of humanities.

The fifth is to enhance the learning ability of the organization members, and the completeness and 
expansibility of the knowledge map, which can not only allow primary and secondary school teachers who are willing to learn to walk freely in the information and knowledge resource base and directly learn and acquire the interested knowledge, but also let them find and learn relevant and extended knowledge in this process. This is particularly helpful to new teachers in primary and secondary schools and teachers with a strong sense of initiative in learning.

Sixth is to promote the standardization of training and professional development of primary and secondary school teacher. For a long time, training activities and professional development of primary and secondary school teachers are in a state of unclear and direct and specific investigation. The training providers (units), training bearers (units) or primary and secondary school teachers participating in training feel the training effect more from the general and non-measurable feelings, but knowledge map not only provides knowledge and path, but also set different points of clear requirements and standards in different nodes. Therefore, it plays an important role in the standardization of primary and secondary teacher training.

\section{EXPLORATION OF THE ESTABLISHMENT OF KNOWLEDGE MAP FOR PRIMARY AND SECONDARY TEACHER TRAINING}

According to the statistics of the Ministry of Education in 2016, up to December 2015, there were totally 256,148 primary and secondary schools in China with 9,341,434 fulltime teachers, including 5,112,774 primary, 2,533,306 secondary school teachers, and 1,695,354 high school teachers in "Table I".

TABLE I. Statistical TABle OF THE Number of High SCHOOls, JUNIOR HigH SCHOOLS AND PRIMARY SCHOOLS, TEACHING STAFF AND FULL-TIME TEACHERS

\begin{tabular}{|c|c|c|c|}
\hline category & $\begin{array}{l}\text { Number of } \\
\text { schools } \\
\text { (unit: } \\
\text { school) } \\
\end{array}$ & $\begin{array}{l}\text { Number of } \\
\text { staff (unit: } \\
\text { person) }\end{array}$ & $\begin{array}{c}\text { Number of } \\
\text { full-time } \\
\text { teachers } \\
\text { (unit: person) }\end{array}$ \\
\hline \multicolumn{4}{|c|}{ high school stage } \\
\hline ordinary high school & 13240 & 2543243 & 1695354 \\
\hline secondary school & 5538 & 1040960 & 521363 \\
\hline senior high school & 6628 & 1286594 & 1121430 \\
\hline Twelve-year school & 1074 & 215689 & 52561 \\
\hline \multicolumn{4}{|c|}{ junior high school stage } \\
\hline junior high school & 37217 & 2809241 & 2533306 \\
\hline nine-year school & 15166 & 1166434 & 494711 \\
\hline Twelve-year school & & & 55992 \\
\hline secondary school & & & 391047 \\
\hline \multicolumn{4}{|c|}{ primary school stage } \\
\hline primary school & 190525 & 5489441 & 5112774 \\
\hline nine-year school & & & 521434 \\
\hline Twelve-year school & & & 50910 \\
\hline
\end{tabular}

http://www.moe.edu.cn/s78/A03/moe_560/jytjsj_2015/2015_qg/201610/t20161012_284511.

Faced with such a large number of primary and secondary school teachers, it is not enough to rely solely on the top-down primary and secondary schools teacher training organized and implemented by education authorities to support professional development, it is of great value for primary and secondary school teacher training to design and develop knowledge map for professional development in line with the independent study and self-development of primary and secondary school teachers.

Gartner Group divides knowledge maps into three types: Conceptual K-map, Process K-map, and Competency K-map [8], which is of enlightening significance and reference value for development of knowledge map for primary and secondary school teachers training. It is a useful exploration and practice to develop the knowledge map for professional development of primary and secondary school teachers by combining the actual needs and reality of professional development of primary and secondary school teachers from the perspective of research and design. Specifically, from the perspective of knowledge, the development and construction of knowledge map for primary and secondary school teacher training is a comprehensive knowledge map integrating subject knowledge, education and teaching practice knowledge, science teaching and research knowledge, moral knowledge, evaluation knowledge, leisure knowledge and quality development; from the perspective of individual professional development of primary and secondary school teachers, it needs to be developed as a whole in the five dimensions of facing procedure setting, facing concept (knowledge content) learning, facing improvement of practical ability, facing learning management and facing selfevaluation; at the same time, it has formed a map of teachers' professional development with common points, and helps the primary and secondary school teachers construct individual knowledge maps with individual personalities through this map. Adding the knowledge map of the organization knowledge map and training institutions (organizations) of primary and secondary schools, the professional development of primary and secondary school teachers will play an important role in knowledge dimension and autonomous learning, and it even can foresee the possible innovations and breakthroughs in management system of primary and secondary teacher training and the current organization mechanism of the primary and secondary school teacher training.

The method of constructing knowledge map for primary and secondary school teachers' training can draw lessons from the method of drawing knowledge map developed by Gartner Group: from the beginning of knowledge audit, we can carry out knowledge mapping, add knowledge index, and form the circulatory system of knowledge outline and personalization, and this kind of circulation can be repeated constantly. Knowledge audit is mainly to complete the knowledge resources and related support theory required by primary and secondary school teachers training, and to determine the professional development of primary and secondary school teachers should know the knowledge, key knowledge and developmental knowledge. Knowledge mapping classifies knowledge assets according to the basic requirements of primary and secondary school teacher training and the new requirements of advancing with the times and classifies relevant knowledge in different fields (knowledge node) combining with professional terminologies formed in primary and secondary school 
teacher training and professional development activities. The key is to mark the relationship between fields, which is the embryonic stage of the knowledge map. The establishment of knowledge index is to carry forward the established knowledge mapping from a static concept to a dynamic concept, forming an index link between the various knowledge domains (knowledge nodes). This index is not only explicit and implicit knowledge, but also includes work (activities) procedures and personnel indexing contacts. The outline of knowledge and personalization mainly describe the relationship between users and other things, including various groups, information resources, external institutions, media, and process procedures in universities, to make these knowledge (domains and nodes) knowledge maps that can be successfully used by primary and secondary school teacher training institution, primary and secondary schools, and primary and secondary school teachers.

\section{CONCLUSION}

Constructing a knowledge map for professional growth and development of primary and secondary school teachers can link all the supporting requirements for development of a primary and secondary school teacher from the learning stage (generally from the university stage) to the beginning of the teacher profession to its subsequent development, including knowledge, resources, and competency training to form a complete system of professional development, and make the overall value of the system greater than the sum of the various parts. This knowledge map is not only a visual navigation tool for curriculum teaching, a tool for integrating knowledge resources, and a powerful tool for training management. It is also a fusion tool for training projects (contents), training development systems, and training implementation organizations. It can even become a thirdparty assessment and auditing management tool. With the application, practice, evolution and improvement of this knowledge map, it will play an irreplaceable role in the professional development and development of primary and secondary school teachers.

\section{REFERENCES}

[1] Long Baoxin. Teacher Training Reform Towards Efficient - A Study on the Situation of Teacher Training Reform in Primary and Middle Schools in current World [J]. Journal of Suzhou University (Educational Science Edition), No. 3, 2015: 120-128.

[2] Wang Ning. Remain vigilant about the phenomenon of "soft resistance" in Primary and Middle Schools teachers' continuing education [J]. Education Review, No. 7, 2014: 60-62.

[3] Zhou Nanzhao, et al. Teacher Educational Reform and Teacher's Professional Development: International Vision and Native Practice [M]. Shanghai: East China Normal University Press, 2007: 27-28.

[4] Wang Mingshuai. From "Being Developed" to "Independent Development" - Realistic Challenges and Possible Countermeasures of Teacher's Professional Development [J]. Teacher Educational Research, 2011, No. 4: 1-6.

[5] Tang Xiaoming. A survey of the educational ecologicalization of teacher training [J]. Teacher Education Forum, No. 2, 2014: 72-75

[6] Long Baoxin. Teacher Training Reform Towards Efficient — A Study on the Situation of Teacher Training Reform in Primary and
Middle Schools in current World [J]. Journal of Suzhou University (Educational Science Edition), No. 3, 2015: 120-128.

[7] https://baike.baidu.com/item/knowledge map/1160378?fr=aladdin.

[8] From: Bao Rong, He Shanyun. Maps Construction: Strategies for Teachers' Personal Knowledge Management [J]. University Education Science, 2008, No. 5: 37-40. 